\title{
How prevalent is aspirin induced asthma?
}

\section{A J Knox}

\section{There is still much to be learned about the genetics and pathogenesis of aspirin induced asthma and the role of prostaglandins and leukotrienes in airways diseases.}

$\mathrm{T}$ he bark of the white willow Salix alba has been used in medicine for thousands of years and was described by Hippocrates in 400BC and by Dioscarides, a Greek surgeon to the Roman Army, in AD70. In the 1700s Edward Stone, the vicar of Chipping Norton, wrote that 20 grains of powered willow bark in a dram of water every 4 hours was an excellent cure for "agues". It was only in 1829 that Leroux discovered that salicin was the active ingredient and in 1859 that Kolbe succeeded in the chemical manufacture of salicylic acid. Felix Hoffmann, a German chemist, added an acetyl group to the molecule in 1897 in an effort to increase its stability and to provide a more effective and safe treatment for his father who was crippled by rheumatism. Aspirin was born. Subsequently, benefits of aspirin have been reported in a wide range of ailments including fevers, inflammatory diseases, stroke, and heart disease. In 1971 Vane and colleagues identified the mechanism of action of aspirin as inhibition of cyclooxygenase, a key enzyme in the generation of prostaglandins from arachidonic acid.

It has become clear, however, that not all the effects of aspirin are beneficial and this is particularly notable in the respiratory tract where a subset of patients with asthma develop an aggressive mucosal inflammatory disease within hours of ingesting aspirin and most other non-steroidal antiinflammatory drugs (NSAIDs). ${ }^{2}$ Aspirin induced asthma forms part of a syndrome which includes rhinitis and nasal polyposis. ${ }^{3}$ Aspirin intolerance is associated with more severe forms of asthma and is more common in women. ${ }^{2} \mathrm{Al}$ though there are a number of theories regarding the pathogenic mechanisms involved in aspirin induced asthma, it seems to be related to inhibition of protective prostaglandins from cyclooxygenase causing an imbalance of proinflammatory leukotrienes. ${ }^{2-5}$ Genetic studies have shown that individuals with a polymorphism in leukotriene (LT) $\mathrm{C}_{4}$ synthase which causes them to produce larger quantities of cysteinyl leukotrienes are more prone to developing aspirin induced asthma. ${ }^{67}$ Most patients with asthma, however, do not bronchoconstrict to aspirin and, indeed, protective beneficial effects have been reported with both oral and inhaled cyclooxygenase inhibitors on a wide range of bronchoconstrictor challenges in patients with asthma. ${ }^{8}$

Studies of aspirin induced asthma in different populations have found prevalences ranging from $1 \%$ to $20 \%$, with the differences being attributed either to the methods of diagnosis or differences in the populations being assessed. ${ }^{9-12}$ The study by Vally et $a l^{13}$ reported in this issue of Thorax looks at the prevalence of aspirin intolerant asthma in three populations of asthmatic subjects in Australia, one cohort recruited from hospital based sources, a second from the Asthma Association of Western Australia, and a third taken from a study of randomly selected individuals from a rural community. The prevalence of respiratory symptoms triggered by aspirin in all three populations was remarkably similar at $10-11 \%$

Estimates of the prevalence of aspirin induced asthma depend on the methods used, however. It has been suggested that the gold standard for diagnosing aspirin induced asthma should be either oral or inhaled challenge with aspirin. ${ }^{14}$ Challenge studies have suggested prevalences as high as $20 \%$ in some populations and it is possible that many patients are diagnosed who did not realise that aspirin made their asthma worse. ${ }^{15}$ Our own anecdotal experience in Nottingham of trying to identify asthmatic patients by oral challenge suggests that these patients are rather more difficult to find than one might expect, based on prevalence figures from questionnaire studies. Interestingly, in the study by Vally et $\mathrm{al}^{13}$ a number of individuals in the random cohort had not been diagnosed as asthmatic but reported respiratory symptoms with aspirin and other NSAIDs, which suggests that these individuals may suffer asthmatic symptoms when challenged with NSAIDs.

Cyclooxygenase, the enzyme responsible for production of prostanoids, exists in two isoforms-COX-l (the constitutive form) and COX-2 (the inducible inflammatory form). ${ }^{16}$ There is evidence that the inflammatory form COX-2 is increased in both human asthma ${ }^{16}$ and in animal models of asthma. ${ }^{17}{ }^{18}$ As COX-1 is predominantly involved in the production of protective housekeeping prostanoids, it has been thought that it is COX-1 inhibition which is responsible for the adverse effects of aspirin. ${ }^{19}$ If this is correct, the new selective COX-2 inhibitors should be less prone to induce aspirin induced asthma. Recent studies suggest that this is, indeed, the case and that adverse respiratory reactions are seen much less commonly with these drugs. ${ }^{2021}$

There is clearly still much to be learned about both the genetics and pathogenesis of aspirin induced asthma and of the role of prostaglandins and leukotrienes in airways diseases. Reports such as the one from Australia ${ }^{13}$ suggest that aspirin induced asthma is an important problem for further study.

\section{Thorax 2002:57:565-566}

Correspondence to: Professor A J Knox, Division of Respiratory Medicine, Clinical Sciences Building, Nottingham City Hospital, Hucknall Road, Nottingham NG5 1PB, UK alan.knox@nottingham.ac.uk

\section{REFERENCES}

1 Vane J. Aspirin and other anti-inflammatory drugs. Thorax 2000;55(Suppl 2):S3-9.

2 Szczeklik A, Niżankowska E. Clinical features and diagnosis of aspirin induced asthma. Thorax 2000;55(Suppl 2):S42-4.

3 Schiavino D, Nucera E, Milani A, et al. The aspirin disease. Thorax 2000;55(Suppl 2):S66-9.

4 Passalacqua G, Ciprandi G, Canonica GW United airways disease: therapeutic aspects. Thorax 2000;55(Suppl 2):S26-7.

5 Leff AR. Role of leukotrienes in bronchial hyperresponsiveness and cellular responses in airways. Thorax 2000;55(Suppl 2):S32-7.

6 Sanak M, Szczeklik A. Genetics of aspirin induced asthma. Thorax 2000;55(Suppl 2):S45-7.

7 Sampson AP, Siddiqui S, Buchanan D, et al Variant LTC $_{4}$ synthase allele modifies cysteinyl leukotriene synthesis in eosinophils and predicts clinical response to zafirlukast. Thorax 2000;55(Suppl 2):S28-31.

8 Pang LH, Pitt A, Petkova D, et al. The COX-1/COX-2 balance in asthma. Clin Exp Allergy 1998;28:1050-8.

9 Hedman J, Kaprio J, Poussa T, et al. Prevalence of asthma, aspirin intolerance nasal polyposis and chronic obstructive pulmonary disease in a population-based study. Int J Epidemiol 1999;28:717-22.

10 McDonald JR, Mathison DA, Stevenson DD. Aspirin intolerance in asthma. Detection by oral challenge. J Allergy Clin Immunol 1972;50: 198-207.

11 Spector SL, Wangaard CH, Farr RS. Aspirin and concomitant idiosyncrasies in adult asthmatic patients. J Allergy Clin Immunol 1979;64:500-6.

12 Falliers CJ. Aspirin and subtypes of asthma: risk factor analysis. J Allergy Clin Immunol 1973;52:141-7

13 Vally H, Taylor ML, Thompson P. The prevalence of aspirin-intolerant asthma (AIA) in Australian asthmatic patients. Thorax 2002;57:569-74.

14 Nizankowska E, Bestynska-Krypel A, Cmiel $A$, et al. Oral and bronchial provocation tests 
with aspirin for diagnosis of aspirin-induced asthma. Eur Respir J 2000;15:863-9.

15 Szczeklik A, Nizankowska E, Duplaga M Natural history of aspirin induced asthma. Eur Respir J 2000:16:432-6.

16 Pang L. COX-2 expression in asthmatic airways: the story so far. Thorax $2001 ; 56: 335-6$

17 Oguma T, Asano K, Shiomi T, et al.

Cyclooxygenase-2 expression during allergic inflammation in guinea-pig lungs. Am J Respir Crit Care Med 2002; 165:382-6.

18 Martin C, Wohlsen A, Uhlig S. Changes in airway resistance by simultaneous exposure to TNF $\alpha$ and IL-1 $\beta$ in perfused rat lungs. Am Physiol 2001;280:L595-601.

19 Bennett A. The importance of COX-2 inhibition for aspirin induced asthma. Thorax 2000;55(Suppl 2):S54-6.
20 Quaratino D, Romano A, Di Fonsa M, et al Tolerability of meloxicam in patients with histories of adverse reactions to non-steroidal anti-inflammatory drugs. Ann Allergy Asthma Immunol 2000;84:613-7.

21 Szczeklik A, Nizankowska E, Bochenek G, et al. Safety of a specific COX-2 inhibitor in aspirin-induced asthma. Clin Allergy $2001 ; 31: 219-25$

\section{Is there more than one inflammatory phenotype in asthma?}

\section{R A O'Donnell, A J Frew}

\section{Circumstantial evidence suggests an important role for neutrophilic airways inflammation in addition to eosinophilic airways inflammation in non-severe asthma.}

T he existence of different clinical phenotypes of asthma is a concept that has excited considerable interest in academic, clinical, and pharmaceutical quarters. The source of this confusion goes back to the original Greek definition of asthma as a description for transient breathlessness. The ancients recognised that the symptoms of asthma could be triggered by cardiac or bronchial disease. The term "cardiac asthma" has been replaced by the physiological and pathological definitions of left ventricular failure and pulmonary oedema. Within bronchial asthma, definitions have continued to focus on physiological measurements and clinical context, including exercise induced asthma, nocturnal asthma, acute severe asthma, occupational asthma, etc. Implicit in these clinical phenotypes is the unspoken assumption that the clinical context dictates the pathophysiological mechanism. The demonstration that eosinophilic inflammation is a characteristic feature of many asthmatic airways led, during the 1990s, to the unhealthy and erroneous view that all asthma might be caused by eosinophils. Indeed, at one stage asthma was in danger of being defined for pharmaceutical purposes as eosinophilic airways inflammation. The few dissenting voices were drowned out by a series of studies showing the "antiinflammatory" effects of anti-asthma drugs by virtue of a proxy effect on airways eosinophilic. Given the known dependence of eosinophils on T cells and cytokines such as interleukin 5 (IL-5), a further dogma arose that all asthma was orchestrated by $\mathrm{T}$ cells producing IL-5 and IL-4, the Th2 cytokines.
This issue of Thorax features a hypothesis paper by Douwes et al that questions the assumption that Th2 driven allergic inflammation is the pathogenetic mechanism behind the majority of cases of asthma. Douwes and colleagues draw from several sources of evidence to argue that non-allergic, non-eosinophilic asthma is more common than is generally appreciated and that neutrophil driven inflammation, similar to that found in occupational asthma, could be the major alternative disease mechanism in these patients. The implication is that neutrophilic airways inflammation is not only a feature of severe asthma, where it has been well documented, ${ }^{2-5}$ but also forms the basis of a distinct inflammatory phenotype which may be present either alone or in conjunction with eosinophilic inflammation. The authors go on to postulate that activation of innate immunity due to inhalation of environmental agents may, as a precipitant of this type of asthma, partly explain the overall rise in the prevalence of asthma in the latter half of the 20th century.

As summarised by the authors, many recent clinical investigations have provided data to support these hypotheses. However, most asthmatic patients recruited to these studies either had severe disease or were on some form of corticosteroid therapy, raising concerns about possible confounding effects on the pattern of inflammation. Airway neutrophilia is often present in samples from the airways of patients with severe asthma, ${ }^{2-5}$ but it is not known whether this is due to frequent exacerbations or a feature of severity in stable chronic severe asthma. Most would agree that clinical severity in asthma may have multiple causes and that patients with severe asthma may have arrived at their clinical phenotype by different routes. It is also well known that oral corticosteroids mobilise neutrophils in healthy subjects. In acute severe asthma the blood neutrophil count is often high at presentation and falls with treatment. We must presume that the fall occurs in response to improved clinical status and reduced biological stress and swamps any rise in neutrophil counts induced by oral corticosteroids. Nevertheless, we should not ignore the possibility of an underlying effect of corticosteroids on neutrophil numbers or activity. Although there is much in vivo evidence that steroids reduce eosinophilic inflammation, the extent to which they genuinely potentiate neutrophil activity is far from clear. It seems unlikely that neutrophilic non-eosinophilic asthma is solely a product of steroid treatment as eosinophilic inflammation can still be found in severe asthma and even in well controlled disease, despite inhaled or oral steroid treatment. ${ }^{67}$ Moreover, not all the evidence supports the theory that steroids augment neutrophilic inflammation in vivo. For example, Louis et al have shown that, in severe asthma, sputum neutrophils are reduced in subjects who are on oral steroids compared with those who are not. ${ }^{7}$ Ideally, a large population study of steroid naïve asthmatic patients is needed to ascertain the prevalence of non-eosinophilic airways inflammation in asthma. ${ }^{8}$ Follow up might reasonably include comparison of sputum neutrophil counts, neutrophil activation markers, and neutrophil chemotactic activity between eosinophilic and noneosinophilic asthmatics both before and after starting normal inhaled steroid treatment.

\section{COMPARISONS WITH COPD}

Neutrophil driven asthma might have much in common with other airways diseases such as bronchiectasis, ${ }^{9}$ cystic fibrosis, ${ }^{10}$ and chronic obstructive pulmonary disease (COPD $)^{11-13}$ in which neutrophil influx is a recognised feature. COPD, like asthma, is a definition rather than a disease. Moreover, there are several definitions of COPD which reflect the parent discipline of the definer. Radiologists, epidemiologists, pathologists, 
physiologists, and clinicians can all offer a working definition of COPD but, just as a set of blind men feeling an elephant cannot readily describe the whole, so the single discipline definition usually focuses on the aspect of COPD they can see or measure. Some subjects with COPD have airflow obstruction despite only having minimal radiological or pathological evidence of emphysema. ${ }^{14}{ }^{15}$ The physiological basis of this airflow limitation is likely to be peripheral airway remodelling changes that include goblet cell hyperplasia ${ }^{16}{ }^{17}$ and increased smooth muscle bulk ${ }^{18}$ which are similar to changes found in asthmatic airways. While a subset of patients with COPD have features more commonly associated with asthma such as eosinophilic and basement membrane thickening, ${ }^{19}$ the converse also appears to be true with some asthmatics having neutrophilia and fixed airflow obstruction. It is interesting that, although there have only been a few bronchoscopic studies of severe asthma, a prominent finding is of an increase in neutrophil numbers in the large airway wall ${ }^{20}$ which has not been found in the majority of studies of COPD. ${ }^{11}{ }^{21-24}$ As yet there is no proven explanation as to why submucosal neutrophil counts are frequently normal in biopsy specimens of patients with COPD, a disease in which the neutrophil is often regarded as the major effector cell. Perhaps future investigations comparing mechanisms of neutrophil recruitment in these two diseases may help to answer this question. Research into mechanisms of airway inflammation in COPD and other neutrophilic airways diseases could also eventually help to identify possible therapeutic targets in this subset of asthma patients.

\section{NEUTROPHILS AND AIRWAY MUCUS OVERPRODUCTION}

Products of the activated neutrophil include reactive oxygen species, cytokines, lipid mediators, and tissue damaging enzymes such as elastase, cathepsin $\mathrm{G}$, and myeloperoxidase. ${ }^{25} 26$ Mucus hypersecretion is a particular hallmark of asthma that recent observations have linked ever more closely to the neutrophil and its products. Neutrophil elastase is a potent secretagogue for both airway epithelial cells ${ }^{27}$ and submucosal gland cells. $^{28}$ Moreover, both neutrophil elastase and reactive oxygen species have been shown in vitro independently to increase epithelial mucin mRNA and protein expression, ${ }^{29-31}$ possibly via ligand independent transactivation of the epidermal growth factor receptor (EGFR). ${ }^{29}$ Mucin gene expression has been proposed as the principal factor governing the differentiation of epithelial cells into goblet cells. ${ }^{32}$ The concept that neutrophils can induce goblet cell metaplasia via EGFR activation in addition to recent evidence that epithelial MUC 5AC and EGFR are co-localised in asthmatic airway epithelial goblet cells would suggest that neutrophil driven goblet cell metaplasia may be a key component of neutrophilic asthma. ${ }^{33}$

\section{POSSIBLE TARGETS FOR TREATMENT}

As in other airways diseases, airway neutrophilia in asthma is likely to be multifactorial, dependent on a complex interplay of chemokines and lipid mediators from both resident airway cells and inflammatory cells in addition to enhanced adhesion molecule expression and neural activity. Thus, it may be difficult to identify the cells or molecules against which targeted treatment might have the most clinical benefit. It is tempting to speculate that epithelial chemokine production and release, perhaps augmented in response to front line exposure to inhaled particulate matter, may be an important early step in the generation of neutrophilic asthma and a valid target for therapeutic intervention. Prevention of the epithelial response might reasonably be expected to arrest the cascade of damage and further chemokine generation caused by responding inflammatory cells and their attendant mediators. One suggested target is interleukin 8 (IL-8), a CXC chemokine produced by bronchial epithelium and one of the most potent neutrophil activators and chemoattractant mediators discovered to date. Epithelial expression of IL-8 is heightened both in vitro and in vivo in response to a range of noxious stimuli, including diesel exhaust particles. ${ }^{34}$ Moreover, IL-8 is found in increased quantities in airway secretions obtained from subjects with neutrophilic airways diseases, including asthma, at concentrations corresponding to the increased numbers of neutrophils in the same samples. ${ }^{38536}$ Whether the epithelium, other resident airway cells such as smooth muscle cells, or infiltrating inflammatory cells are the principal source of increased luminal IL-8 levels in asthma remains uncertain.

\section{"although an important role for neutrophilic airways inflammation in non-severe asthma has yet to be confirmed, there is much circumstantial evidence to support its existence"}

Another possible drug target is leukotriene $\mathrm{B}_{4}\left(\mathrm{LTB}_{4}\right)$, an important neutrophil product that is produced by a variety of other cells. A study of lung secretions of patients with COPD and bronchiectasis showed that $43 \%$ of neutrophil chemotactic activity was dependent on IL-8 and a further $27 \%$ was dependent on $\mathrm{LTB}_{4}{ }^{37}$ In addition, $\mathrm{LTB}_{4}$ has been found in increased quantities in bronchoalveolar lavage (BAL) fluid of subjects with asthma compared with controls, despite high doses of oral corticosteroids. ${ }^{2}$ Of the two types of leukotriene modulating treatments currently available-the 5-lipoxygenase inhibitors and cysteinylleukotriene (cys-LT) receptor antagonists-only 5-lipoxygenase inhibitors inhibit the activity of $\mathrm{LTB}_{4}$, a fact that might warrant exploration of the relative benefits of 5-lipoxygenase inhibitors versus cys-LT receptor antagonists in neutrophilic asthma.

\section{INDUCED SPUTUM IN CLINICAL PRACTICE}

The existence of different asthma inflammatory phenotypes that may respond differently to treatment would argue in favour of the more widespread use in clinical practice of induced sputum, until now predominantly a research tool. Practical considerations including cost, technical expertise, and the technician time needed to process samples and count inflammatory cell populations would prohibit its use in the diagnosis and monitoring of all cases of suspected asthma. ${ }^{38}$ However, in those subjects in whom disease control is proving difficult, sputum induction might be valuable in differentiating between patients with poorly suppressed allergic inflammation, who may be more likely to benefit from increased conventional asthma treatment, and those with non-eosinophilic inflammation who require alternative approaches.

\section{CONCLUSIONS}

In summary, although an important role for neutrophilic airways inflammation in non-severe asthma has yet to be confirmed, there is much circumstantial evidence to support its existence. Future research into the clinical characteristics and pharmacological responses of this form of asthma might yield results relevant not only to asthma, but also to other neutrophilic airway diseases.

Thorax 2002;57:566-568

\section{Authors' affiliations}

R A O'Donnell, A J Frew, University Medicine, Southampton General Hospital, Southampton SO16 6YD, UK

Correspondence to: Dr R A O'Donnell, University Medicine, Southampton General Hospital, Southampton SO16 6YD, UK; ROD1@soton.ac.uk

\section{REFERENCES}

1 Douwes J, Gibson P, Pekkanen J, et al. Non-eosinophilic asthma: importance and 
possible mechanisms. Thorax

2002;57:643-8

2 Wenzel SE, Szefler SJ, Leung DY, et al. Bronchoscopic evaluation of severe asthma. Persistent inflammation associated with high dose glucocorticoids. Am J Respir Crit Care Med 1997;156:737-43.

3 Ordonez CL, Shaughnessy TE, Matthay MA, et al. Increased neutrophil numbers and IL-8 levels in airway secretions in acute severe asthma: clinical and biologic significance. Am J Respir Crit Care Med 2000;161:1 185-90.

4 Fahy JV. Prominent neutrophilic inflammation in sputum from subjects with asthma exacerbation. J Allergy Clin Immunol 1995; 95:843-52.

5 Sur S, Crotty TB, Kephart GM, et al. Sudden-onset fatal asthma. A distinct entity with few eosinophils and relatively more neutrophils in the airway submucosa? Am Rev Respir Dis 1993:148:713-9.

6 Giannini D, Di-Franco A, Cianchetti S, et al. Analysis of induced sputum before and after withdrawal of treatment with inhaled corticosteroids in asthmatic patients. Clin Exp Allergy 2000;30:1777-84.

7 Louis R, Lau LC, Bron AO, et al. The relationship between airways inflammation and asthma severity. Am J Respir Crit Care Med 2000;161:9-16.

8 Gibson PG, Simpson JL, Saltos N. Heterogeneity of airway inflammation in persistent asthma: evidence of neutrophilic inflammation and increased sputum interleukin-8. Chest 2001:119:1329-36.

9 Fahy JV, Schuster A, Ueki I, et al. Mucus hypersecretion in bronchiectasis. The role of neutrophil proteases. Am Rev Respir Dis 1992;146:1430-3

10 Khan TZ. Early pulmonary inflammation in infants with cystic fibrosis. Am J Respir Crit Care Med 1995;151:1075-82.

11 Lacoste JY, Bousquet J, Chanez P, et al. Eosinophilic and neutrophilic inflammation in asthma, chronic bronchitis, and chronic obstructive pulmonary disease. J Allergy Clin Immunol 1993;92:537-48

12 Linden M, Rasmussen JB, Piitulainen $\mathrm{E}$, et al. Airway inflammation in smokers with nonobstructive and obstructive chronic bronchitis. Am Rev Respir Dis 1993; 148: 1226-32

13 Thompson AB, Daughton D, Robbins RA, et al. Intraluminal airway inflammation in chronic bronchitis. Characterization and correlation with clinical parameters. Am Rev Respir Dis 1989;140: 1527-37.
14 Gelb AF, Schein M, Kuei J, et al, Limited contribution of emphysema in advanced chronic obstructive pulmonary disease. Am Rev Respir Dis 1993;147:1 157-61.

15 Burrows B. The emphysematous and bronchial types of chronic airways obstruction. Lancet 1966:830-5.

16 Aikawa T, Shimura S, Sasaki H, et al. Marked goblet cell hyperplasia with mucus accumulation in the airways of patients who died of severe acute asthma attack. Chest 1992;101:916-21.

17 Nagai A, West WW, Paul JL, et al. The National Institutes of Health intermittent positive-pressure breathing trial: pathology studies. I. Interrelationship between morphologic lesions. Am Rev Respir Dis 1985; 132:937-45.

18 Kuwano K, Bosken CH, Pare PD, et al. Small airways dimensions in asthma and in chronic obstructive pulmonary disease. Am Rev Respir Dis 1993; 148:1220-5.

19 Chanez P, Vignola AM, O'Shaugnessy T, et al. Corticosteroid reversibility in COPD is related to features of asthma. Am J Respir Crit Care Med 1997;155:1529-34.

20 Wenzel SE, Schwartz LB, Langmack EL, et al. Evidence that severe asthma can be divided pathologically into two inflammatory subtypes with distinct physiologic and clinical characteristics. Am J Respir Crit Care Med 1999; 160:1001-8

21 Saetta M, Di Stefano A, Maestrelli P, et al. Activated T-lymphocytes and macrophages in bronchial mucosa of subjects with chronic bronchitis. Am Rev Respir Dis 1993;147:301-6

22 O'Shaughnessy TC, Ansari TW, Barnes NC, et al. Inflammation in bronchial biopsies of subjects with chronic bronchitis: inverse relationship of CD8+ T lymphocytes with $\mathrm{FEV}_{1}$. Am J Respir Crit Care Med 1997; 155:852-7.

23 Rutgers SR, Postma DS, ten Hacken NH, et al. Ongoing airway inflammation in patients with COPD who do not currently smoke. Thorax 2000;55:12-8.

24 Di Stefano A, Turato G, Maestrelli P, et al. Airflow limitation in chronic bronchitis is associated with $\mathrm{T}$ lymphocyte and macrophage infiltration of the bronchial mucosa. Am J Respir Crit Care Med 1996; 153:629-32

25 Hiemstra PS, van Wetering S, Stolk J. Neutrophil serine proteinases and defensins in chronic obstructive pulmonary disease: effects on pulmonary epithelium. Eur Respir J 1998;12:1200-8.
26 Tetley TD. New perspectives on basic mechanisms in lung disease. 6. Proteinase imbalance: its role in lung disease. Thorax 1993;48:560-5.

27 Breuer R, Christensen TG, Lucey EC, et al. An ultrastructural morphometric analysis of elastase-treated hamster bronchi shows discharge followed by progressive accumulation of secretory granules. Am Rev Respir Dis 1987;136:698-703.

28 Nadel JA. Role of mast cell and neutrophil proteases in airway secretion. Am Rev Respir Dis 1991;144:S48-51.

29 Takeyama K, Dabbagh K, Jeong Shim J, et al. Oxidative stress causes mucin synthesis via transactivation of epidermal growth factor receptor: role of neutrophils. J Immunol 2000;164:1546-52.

30 Voynow JA, Young LR, Wang Y, et al. Neutrophil elastase increases MUC5AC mRNA and protein expression in respiratory epithelial cells. Am J Physio 1999;276:L835-43.

31 Fischer B, Voynow J. Neutrophil elastase induces MUC5AC messenger RNA expression by an oxidant-dependent mechanism. Chest 2000;117(5 Suppl 1):317-20S.

32 Rogers DF. Airway goblet cells: responsive and adaptable front-line defenders. Eur Respir J 1994;7:1690-706.

33 Takeyama K, Fahy JV, Nadel JA. Relationship of epidermal growth factor receptors to goblet cell production in human bronchi. Am J Respir Crit Care Med 2001;163:511-6.

34 Salvi SS, Nordenhall C, Blomberg A, et al. Acute exposure to diesel exhaust increases IL-8 and GRO-alpha production in healthy human airways. Am J Respir Crit Care Med 2000;161:550-7.

35 Hill AT, Bayley D, Stockley RA. The interrelationship of sputum inflammatory markers in patients with chronic bronchitis. Am J Respir Crit Care Med 1999;160:893-8.

36 Stockley RA, Bayley D, Hill SL, et al. Assessment of airway neutrophils by sputum colour: correlation with airways inflammation. Thorax 2001;56:366-72.

37 Mikami M, Llewellyn-Jones CG, Bayley D, et al. The chemotactic activity of sputum from patients with bronchiectasis. Am J Respir Crit Care Med 1998; 157:723-8.

38 Magnussen $\mathbf{H}$, Holz O, Sterk PJ, et al. Noninvasive methods to measure airway inflammation: future considerations. Eur Respir J 2000;16:1175-9. 